\title{
Fundamentos e testes preliminares de resistência a erosão em concretos refratários
}

\author{
(Erosion resistance of refractory castables)
}

\author{
V. A. A. dos Santos ${ }^{1}$, F. A. O. Valenzuela ${ }^{1}$, J. B. Gallo ${ }^{2}$, V. C. Pandolfelli ${ }^{1}$ \\ ${ }^{1}$ Grupo de Engenharia de Microestrutura de Materiais - GEMM \\ Departamento de Engenharia de Materiais, Universidade Federal de S. Carlos \\ Rod. Washington Luiz, km 235, C.P. 676, S. Carlos, SP, 13565-905 \\ ${ }^{2}$ Departamento de Aplicações e Desenvolvimento, Alcoa Alumínio S.A. \\ Rod. Poços-Andradas, km 10, Poços de Caldas, MG, Brasil \\ vitoem99@uol.com.br, vicpando@power.ufscar.br
}

\begin{abstract}
Resumo
O desgaste de revestimentos refratários é um dos principais problemas em processos industriais onde as linhas de transferência estão sujeitas à alta velocidade de fluidos contendo partículas sólidas. Os trabalhos encontrados na literatura sobre desgaste erosivo em materiais refratários são raros. Como conseqüência, o desenvolvimento de materiais mais resistentes à erosão tem sido lento e, em geral, por meios empíricos. Este trabalho teve como objetivos apresentar uma revisão sobre a importância da erosão nas aplicações industriais e averiguar a resistência ao desgaste de concretos refratários em unidades de fabricação de alumínio e em petroquímicas. As variáveis avaliadas foram: o ângulo de impacto, a pressão da linha, a granulometria e a dureza do agente erosivo, e a temperatura do tratamento térmico a que o material foi submetido. Verificou-se que o histórico do tratamento térmico pode levar a comportamentos distintos quanto ao desgaste erosivo, devido a mudanças nas características dos aditivos ligantes usados em cada material. Constatou-se que o maior desgaste ocorre com um ângulo de impacto de $90^{\circ}$ entre o jato erosivo e o material, decrescendo gradativamente até o ângulo de $30^{\circ}$. Verificou-se também que maiores valores de velocidade, dureza e raio da partícula resultam em maior erosão.
\end{abstract}

Palavras-chave: concreto refratário, erosão por impacto, desgaste.

\begin{abstract}
The wear of refractory linings is often a critical problem in process units where transfer lines are subject to high velocity gas stream containing solid particles. Knowledge related to erosive wear of refractories linings under these conditions is restricted, as consequence, technological development is slow and, in general, developed in an empirical way. The goals of the present work were to review relevant aspects regarding erosive wear on industrial applications and to investigate the erosion resistance of refractory castables currently used by the aluminum industry and in catalyst cracking units. The parameters evaluated were: particle impingement angle, line pressure, particle size and hardness, and thermal history of refractories. It was observed that the plastic refractories submitted to different thermal treatments exhibited distinct erosion resistance behavior, likely due to changes in the binding agents. In addition, it was verified that the higher wear rate was obtained at $90^{\circ}$ of impingement, and decreased slightly as the angle approached $30^{\circ}$. The results also pointed out that erosion was proportional to particle velocity, its hardness and size.
\end{abstract}

Keywords: refractory castable, erosion by impact, wear.

\section{INTRODUÇÃO}

Concretos refratários são usados em áreas onde a resistência à erosão e altas temperaturas são requeridas simultaneamente. Nas unidades integradas de fabricação de alumínio, por exemplo, tais solicitações são verificadas nos equipamentos utilizados na calcinação do hidróxido de alumínio. Nos calcinadores de leito fluidizado, o hidróxido de alumínio é transportado por dutos que operam a temperaturas de até $1250{ }^{\circ} \mathrm{C}$. Linhas de transferência, vasos de retenção e fornos revestidos com materiais refratários que fazem uso deste processo estão sujeitos ao desgaste por erosão, devido ao impacto de partículas a altas velocidades.
Massas plásticas e concretos refratários têm sido também usados em aplicações semelhantes no transporte de catalisadores da indústria petroquímica, onde a velocidade das partículas chega a $30 \mathrm{~m} / \mathrm{s}$ [1]. Visando reduzir os custos de manutenção e o risco de paradas não planejadas da linha de produção, faz-se necessário o uso de materiais refratários mais resistentes à erosão.

Apesar da relevância do assunto, há um número limitado de artigos publicados e de pesquisas direcionadas à erosão de refratários, levando a um desenvolvimento lento e empírico. O presente trabalho é uma revisão atualizada sobre os desenvolvimentos alcançados na área de erosão de concretos refratários. Para se chegar a um entendimento inicial sobre o 
assunto, é feito um relato sobre os problemas apresentados em unidades de fabricação de alumínio e em petroquímicas. A seguir, faz-se uma breve apresentação sobre a ciência e os tratamentos teóricos do desgaste por erosão. Por último, são apresentados e discutidos resultados preliminares de resistência a erosão de concretos refratários.

\section{Erosão nas aplicações industriais}

A seleção do concreto refratário para linhas de transferência depende de uma série de fatores incluindo a vida operacional planejada para o equipamento, o custo do revestimento, sua qualidade, parâmetros de projeto, dimensões do equipamento, material a ser transportado, velocidade do fluxo e ataque químico [2].

A abrasão está relacionada ao desgaste ocorrido quando partículas duras se movimentam paralelamente à superfície de um material. Erosão, no entanto, é a perda progressiva de material de uma superfície devido ao impacto de um fluido, que pode ser um líquido e/ou partículas sólidas [3]. Devido à amplitude dessas definições, a norma ASTM G 40-95 recomenda que seja indicado o mecanismo relevante para cada situação. Neste estudo, o desgaste enfocado é a erosão por impacto de partículas sólidas.

A erosão é característica em aplicações industriais onde altas velocidades de partículas e turbulência no fluxo de líquidos e gases são encontradas. A erosão se torna um problema quando a velocidade de fluxo atinge $3 \mathrm{~m} / \mathrm{s}$, sendo muito severa, ainda que para baixa concentração de partículas, a velocidades superiores a $30 \mathrm{~m} / \mathrm{s}$ [4].

Analisando o projeto de calcinadores para unidades de produção de alumínio, percebe-se a existência de mudanças bruscas na direção dos efluentes gasosos. Estas alterações de curso fazem com que as partículas transportadas atinjam as paredes internas dos dutos em alta velocidade, provocando o desgaste do revestimento. Mudanças no projeto do equipamento visando a redução da velocidade das partículas e melhorias no refratário utilizado como revestimento podem trazer grandes benefícios, aumentando o tempo de operação contínua deste tipo de equipamento. No entanto, tais alterações muitas vezes são inviáveis, direcionando a seleção de materiais refratários com superior resistência ao desgaste.

\section{Erosão de materiais}

Os parâmetros que controlam o desgaste por erosão podem ser divididos em propriedades do fluido, das partículas e do material alvo. Este trabalho se atém somente aos dois últimos itens.

As propriedades das partículas que influenciam na erosão são sua velocidade, tamanho, forma, densidade e ângulo de impacto. Já o material alvo depende do projeto de sua microestrutura, da dureza e da tenacidade. Segundo Ruff e Wiederhorn [5] o principal parâmetro que controla a taxa de erosão de materiais é a velocidade da partícula.
Quanto ao material alvo, os trabalhos têm se concentrado em duas áreas principais: minimização de defeitos no material e sua dureza. Oh [6] sugere que falhas superficiais são catalisadores para o início de propagação de trincas durante o uso. Assim, a profundidade e a distribuição das trincas superficiais influenciam na taxa de erosão. Seus argumentos se baseiam ainda na relação da erosão com o módulo de Weibull [7] que expressa a distribuição estatística de defeitos no material. Para tanto, são apresentadas evidências claras que a estrutura superficial é um fator importante no desgaste por erosão.

A influência da dureza do material alvo tem sido o fator diferencial entre os dois principais modelos propostos para materiais frágeis, apresentados a seguir.

\section{Ciência da erosão}

Uma representação do crescimento de trincas durante o impacto da partícula é mostrada na Fig. 1 [8]. Trincas radiais são formadas quando a superfície está sob carregamento

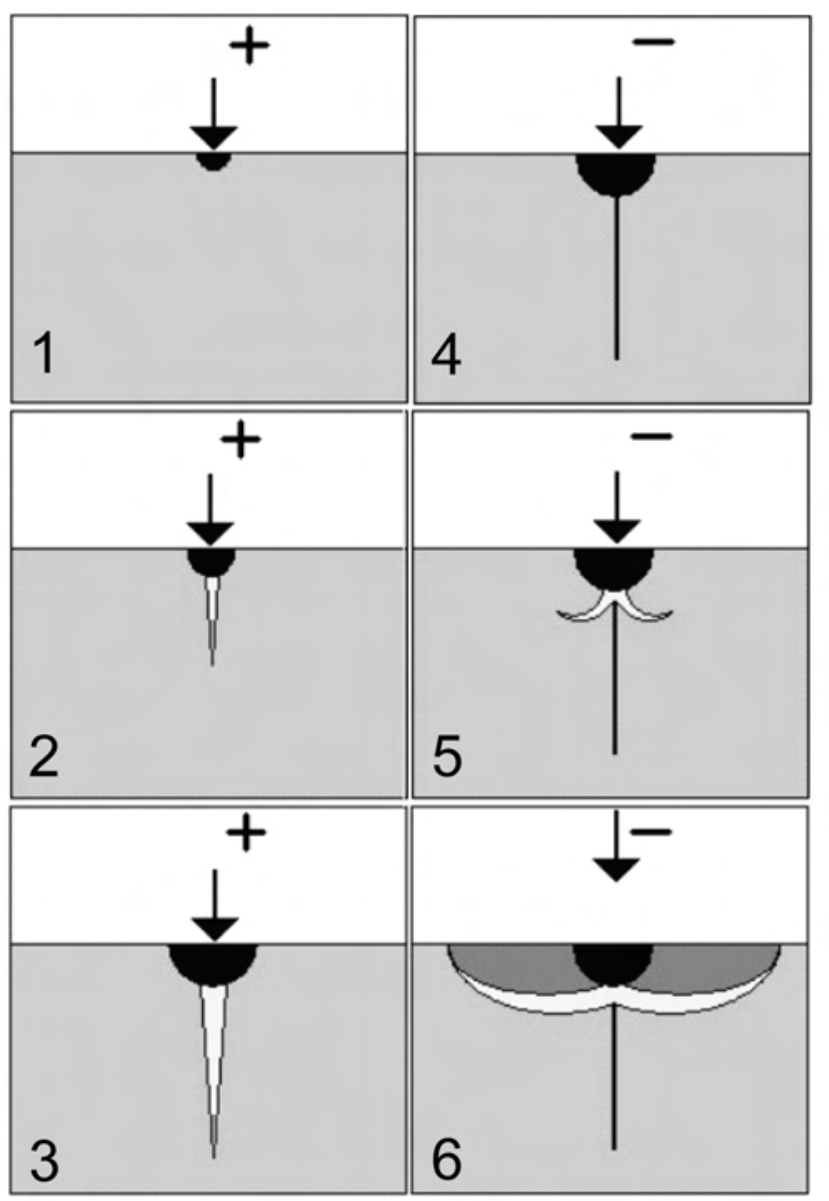

Figura 1: Crescimento de trinca durante o impacto da partícula. O sinal (+) representa a superfície sob carregamento e o (-) indica a retirada de carga por parte da partícula. A região escura denota deformação irreversível [8].

[Figure 1: Crack growth during sharp impact. (+) indicates loading and (-) the unloading. Dark area denotes irreversible strain [8].] 
durante o impacto. São orientadas perpendicularmente à superfície e agem principalmente na degradação da resistência mecânica do material. As trincas laterais, por sua vez, estão mais relacionadas ao desgaste por erosão e se formam paralelamente à superfície do material, assim que a partícula deixa de solicitá-la.

Os modelos mais aceitos na descrição da erosão de cerâmicas densas são o de Evans [9] e o de WiederhornLawn [10]. Nestes dois modelos, assume-se que o impacto da partícula é normal à superfície do alvo. Outra aproximação feita em ambos é que a erosão é dada como a somatória do impacto de partículas isoladas, sem que haja interação entre elas. Adicionalmente, consideram a ocorrência da erosão inteiramente por propagação de trincas e quebra de partes do material. A diferença principal entre os modelos é quanto a suposta contribuição da deformação plástica no processo de formação de trincas. O modelo desenvolvido por Evans [9] assume que a taxa de erosão é proporcional à quantidade de material removido em cada impacto isolado. $\mathrm{O}$ volume erodido, $\mathrm{V}$, é calculado a partir da profundidade de penetração e do tamanho máximo das trincas laterais geradas durante o impacto. Assim, o modelo que descreve a taxa de erosão é obtido:

$$
\mathrm{V} \propto \mathrm{V}_{0}{ }^{19 / 6} \cdot \mathrm{r}^{11 / 3} \cdot \rho^{19 / 12} \cdot \mathrm{K}_{\mathrm{IC}}{ }^{-4 / 3} \cdot \mathrm{H}^{-1 / 4}
$$

onde $\mathrm{V}$ : volume erodido $\left(\mathrm{m}^{3}\right), \mathrm{v}_{\mathrm{o}}$ : velocidade da partícula $(\mathrm{m} / \mathrm{s}), \mathrm{r}$ : raio da partícula $(\mathrm{m}), \rho$ : densidade da partícula $\left(\mathrm{kg} / \mathrm{m}^{3}\right), \mathrm{K}_{\mathrm{IC}}$ : fator de intensidade de tensão crítico do alvo $\left(\mathrm{Pa}^{\mathrm{m}} \mathrm{m}^{1 / 2}\right)$ e $\mathrm{H}$ : dureza do material alvo $(\mathrm{Pa})$.

A teoria elasto-plástica usada por Wiederhorn e Lawn [10] pode também ser aplicada em tratamentos teóricos de erosão. Assumindo que o tamanho da trinca lateral é proporcional ao tamanho da trinca radial, e que a profundidade das trincas laterais é proporcional a penetração máxima de partícula, a seguinte expressão para a taxa de erosão pode ser obtida:

$$
\mathrm{V} \propto \mathrm{v}_{0}^{22 / 9} \cdot \mathrm{r}^{11 / 3} \cdot \rho^{11 / 9} \cdot \mathrm{K}_{\mathrm{IC}}^{-4 / 3} \cdot \mathrm{H}^{-1 / 9}
$$

Essa teoria se aplica de maneira mais adequada a altas temperaturas, quando o desgaste ocorre tanto de maneira frágil, com a formação de trincas laterais, como dúctil, com a presença de deformação plástica.

Ainda que as teorias apresentadas acima tenham sido baseadas em dados experimentais, a sua aplicação para outros materiais cerâmicos difere significativamente. Considerando as complexidades do processo de erosão, as simplificações assumidas e o uso de teorias que descrevem cerâmicas densas, e não concretos refratários, estudos e experimentos adicionais são necessários para um melhor entendimento do processo de erosão de materiais refratários. Uma das razões desta diferença está associada ao tipo de microestrutura dos materiais refratários, constituído de grandes agregados e uma matriz com pequenas partículas.

\section{"Efeito sombra"}

O modelo mais aceito na descrição da erosão de concretos refratários é conhecido como "efeito sombra" [11]. Este modelo aproxima os agregados a esferas e supõe que estas são completamente resistentes à erosão. Assim, somente a área da matriz localizada entre as esferas é erodida por impacto direto das partículas. À medida que a erosão da matriz ocorre, os agregados se sobressaem em relação à superfície, protegendo a matriz por meio do "efeito sombra". Este modelo sugere que a dependência entre o desgaste por erosão e o ângulo de impacto é determinada pelo tamanho e espaço entre os maiores agregados presentes no concreto.

$$
A=2 \cdot\left[1-\frac{\mathrm{R}}{\operatorname{sen} \alpha}\right]
$$

onde $\mathrm{A}$ : área total exposta à erosão $\left(\mathrm{mm}^{2}\right), \mathrm{R}$ : raio do agregado (mm) e $\alpha$ : ângulo de impacto.

\section{MATERIAIS E MÉTODOS}

Neste trabalho utilizaram-se lajotas refratárias silicoaluminosas (LSA), vidro soda-cal (V), massas plásticas refratárias comerciais de alta resistência à erosão (CA, CB e CC) e um concreto refratário de alta alumina desenvolvido pelo próprio laboratório onde a pesquisa foi realizada (concreto G).

A resistência à erosão foi determinada por meio do ensaio em tréplica [12] em corpos de prova de formato retangular, nas dimensões nominais de $115 \mathrm{~mm}$ x $115 \mathrm{~mm}$ x $25 \mathrm{~mm}$ [13]. Os procedimentos realizados neste trabalho subdividem-se na calibração do equipamento, na preparação dos corpos de prova e na correlação da erosão com algumas variáveis, tais como parâmetros do ensaio, propriedades do material e histórico térmico do concreto refratário.

\section{Descrição do equipamento}

O equipamento utilizado é apresentado na Fig. 2, consistindo essencialmente de uma câmara de metal, um regulador de pressão e um ejetor de material erosivo. O ejetor, como mostrado na Fig. 3, é composto pelas entradas de ar e de material erosivo, e pela guia do tubo de vidro. $\mathrm{O}$ tubo de vidro deve ser substituído a cada ensaio para evitar variação no diâmetro interno e na velocidade da partícula.

\section{Calibração do equipamento}

No intuito de assegurar a reprodutibilidade dos ensaios realizados, fez-se a calibração do equipamento utilizando corpos de prova de vidro soda-cal. A escolha desse material se deve ao baixo preço e homogeneidade microestrutural. A NBR 13186 exige uma diferença inferior a $0,5 \mathrm{~cm}^{3}$ entre os valores máximo e mínimo [12]. Após a realização do ensaio em triplicata, os resultados obtidos se mostraram adequados 


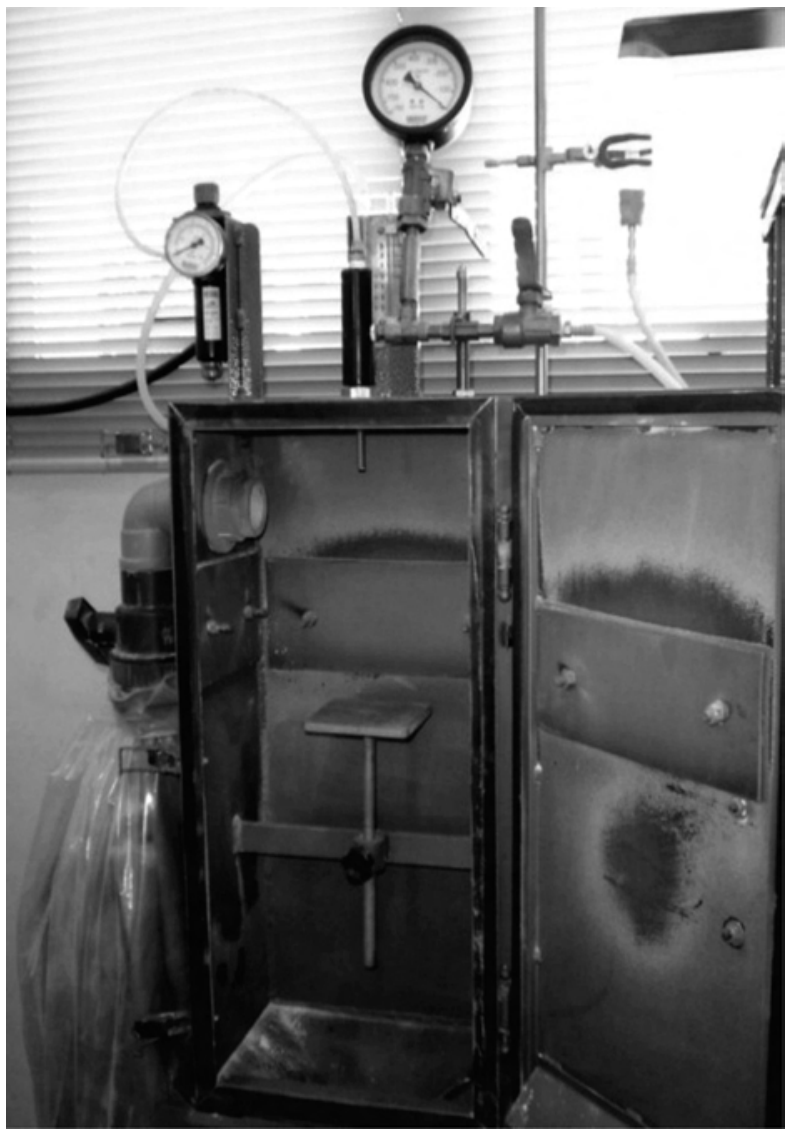

Figura 2: Erosímetro.

[Figure 2: Erosion testing equipment.]

em relação ao recomendado pela norma, com a diferença inferior a $0,1 \mathrm{~cm}^{3}$ entre os valores máximo e mínimo.

O carbeto de silício (EC6-F036, Treibacher Schleifmittel, Brasil) utilizado seguiu as recomendações da norma ABNT [14], sendo caracterizado via série de peneiras para se garantir a constância da distribuição granulométrica.

\section{Preparação dos corpos de prova}

As massas plásticas foram processadas em um reômetro para concretos [15] e moldadas manualmente com dimensões de 115 x 115 x 25 mm. Após 24 h de cura em temperatura e umidade ambiente, os corpos foram retirados do molde e secos em estufa a $110{ }^{\circ} \mathrm{C}$ também por um período de $24 \mathrm{~h}$.

Baseado no "efeito sombra", Engman [16] mostra a importância de se alcançar um estado de equilíbrio superficial antes da realização do teste, uma vez que a taxa de desgaste por erosão é dependente da região em que se realiza o ensaio. Em seu estudo, é proposto o uso de uma "pré-erosão" mínima para que o ensaio seja realizado a partir de um nível de profundidade do corpo que não sofra influência da superfície.

No intuito de expor sua real microestrutura, evitar trincas superficiais induzidas pela moldagem e avaliá-los em

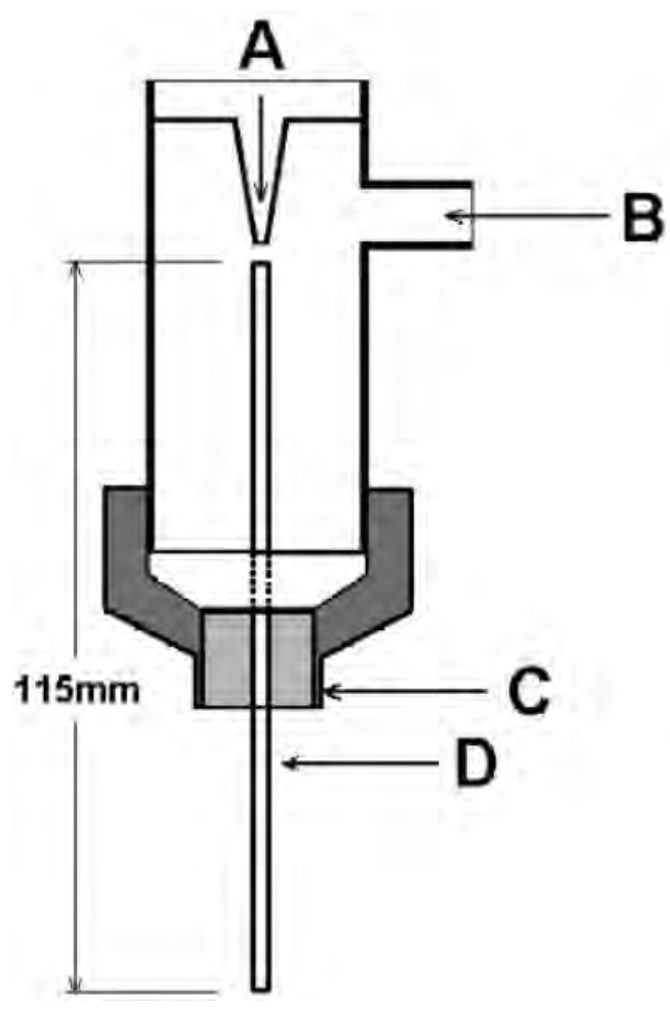

Figura 3: Conjunto do ejetor: (A) Bico de ar; (B) Entrada de erosivo; (C) Guia do tubo de vidro; (D) Tubo de vidro.

[Figure 3: Sand blast mechanism: (A) Air nozzle; (B) Erosion media orifice; (C) Stabilizing sleeve; (D) Glass tube.]

condições mais próximas do uso $[6,16]$, os corpos foram retificados a úmido e novamente secos a $110{ }^{\circ} \mathrm{C}$ por $24 \mathrm{~h}$. A partir de estudo anterior efetuado pelos autores, se pôde concluir que o fato da etapa de retificação ser a úmido ou a seco não interfere nos resultados, optando-se pela primeira pois o líquido evita o aquecimento excessivo do rebolo e a liberação de grandes quantidades de pó no ambiente. Foram também preparados corpos de prova a partir das lajotas (LSA), cortando-as nas dimensões adequadas ao ensaio.

\section{Parâmetros de ensaio}

Inicialmente, para se ter uma melhor compreensão do ensaio e suas variáveis, foram realizados estudos sobre a influência dos parâmetros mais relevantes na erosimetria, tais como, pressão da linha de ar, ângulo de impacto e tipo de material abrasivo.

A lajota silico-aluminosa (LSA) e a massa plástica CA - dois materiais de durezas bem distintas - foram submetidos ao ensaio de resistência à erosão sob diversas pressões de linha, devidamente ajustadas e medidas através de válvula e manômetro presentes no equipamento para este fim. Neste caso, a variação na pressão de linha afeta diretamente a pressão de vácuo dentro da câmara. Seguindo recomendações da norma 
[12], os resultados foram expressos em função da pressão de vácuo, medido por um vacuômetro presente no equipamento.

Esta mesma massa plástica teve sua resistência à erosão avaliada em função do ângulo de impacto (fazendo uso de um apoio reclinável para o corpo de prova) e do tipo do material erosivo. Além de carbeto de silício, foram usados como erosivo alumina calcinada (A1, Alcoa, Brasil) e hidróxido de alumínio (C-30, Alcoa, Brasil), conforme a Tabela I.

\section{Características do material alvo}

Foram ensaiados três tipos de massas plásticas (CA, CB, $\mathrm{CC}$ ), um concreto refratário (CG), lajotas silico-aluminosas (LSA) e vidro soda-cal (V), com o intuito de correlacionar o desgaste erosivo com seus valores de porosidade.

\section{Histórico térmico do material alvo}

Avaliou-se também a influência da temperatura de queima que as massas plásticas e o concreto refratário foram submetidos, com o intuito de se verificar se os materiais testados apresentam alguma alteração significativa de comportamento devido a possíveis mudanças nas características dos seus aditivos ligantes. Para isso, utilizouse uma taxa de aquecimento de $1^{\circ} \mathrm{C} / \mathrm{min}$ e $5 \mathrm{~h}$ de patamar na temperatura de tratamento térmico, conforme procedimentos usuais de utilização em industrias petroquímicas.

\section{RESULTADOS E DISCUSSÃO}

\section{Parâmetros de ensaio}

Na Fig. 4 é apresentado o efeito da pressão de vácuo em 2 tipos de materiais (CA e LSA). O material LSA não é usado para aplicações onde se requer alta resistência a erosão, pois apresenta elevada porosidade e é constituído por

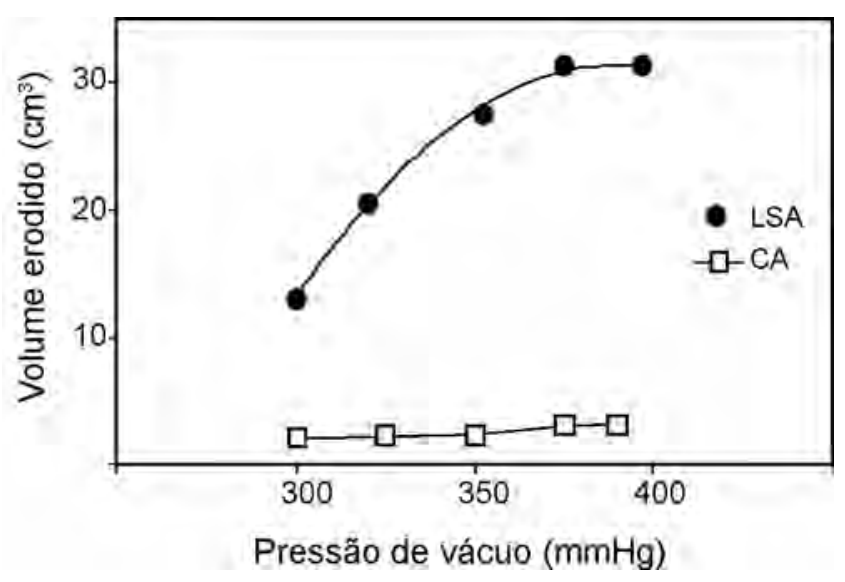

Figura 4: Variação de volume a diferentes pressões de vácuo para materiais com distinta resistência ao desgaste.

[Figure 4: Effect of induced vacuum on volume loss of distinct erosion resistance materials.] fases cristalinas e amorfas de baixa dureza. O material com maior dureza - CA - se mostrou mais resistente ao desgaste por erosão e menos suscetível à influência da variação de pressão [17]. Diferentemente dos estudos subseqüentes, este não foi realizado em tréplica e, por isso, não apresenta desvio em seus resultados.

A partir desse estudo, adotou-se $400 \mathrm{mmHg}$ como pressão de vácuo padrão, uma vez que impõe as condições mais severas de ensaio dentre as pressões analisadas e por se tratar do valor recomendado pela norma.

Na Fig. 5 é apresentada a dependência da erosão com o ângulo de impacto para corpos de prova CA. Para ângulos inferiores a $30^{\circ}$, não foram realizados ensaios devido a impossibilidade de assegurar a confiabilidade dos resultados, uma vez que a área disponível para erosão se torna muito pequena. $\mathrm{O}$ desgaste por erosão é máximo a um ângulo de impacto de $90^{\circ}$, reduzindo gradualmente até o ângulo de $30^{\circ}$. Esse comportamento é similar ao apresentado em outros estudos com concreto refratário e com vidro, ainda que no caso do vidro a redução da erosão em função do ângulo é mais intensa [18]. Assim, o comportamento da erosão de materiais refratários se assemelha ao de materiais frágeis (Fig. 6) [5], exibindo pouca ou nenhuma deformação plástica quando avaliado à temperatura ambiente.

$\mathrm{Na}$ erosimetria, desvios de aproximadamente $10 \%$ não

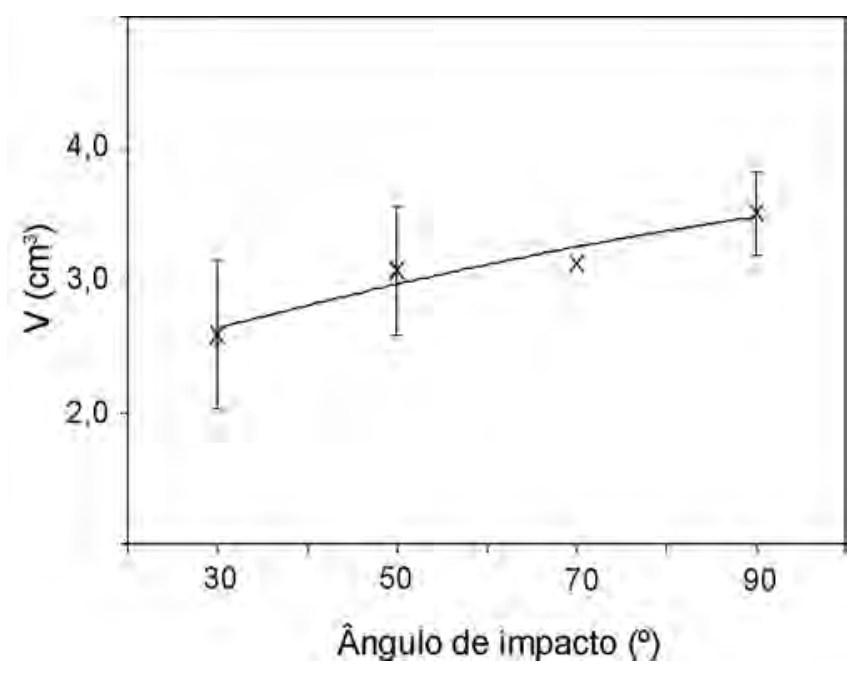

Figura 5: Efeito do ângulo de impacto na variação de volume do concreto A.

[Figure 5: Effect of impingement angle on volume loss of castable A.]

são raros entre ensaios realizados sob as mesmas condições devido à complexidade da microestrutura dos corpos de massa plástica e de concretos refratários. Como estes materiais sofrem uma redução de volume muito pequena, a perda de um único agregado pode gerar diferenças consideráveis entre dois ensaios semelhantes. Quanto menor o ângulo de impacto, de um modo geral, maior tem 


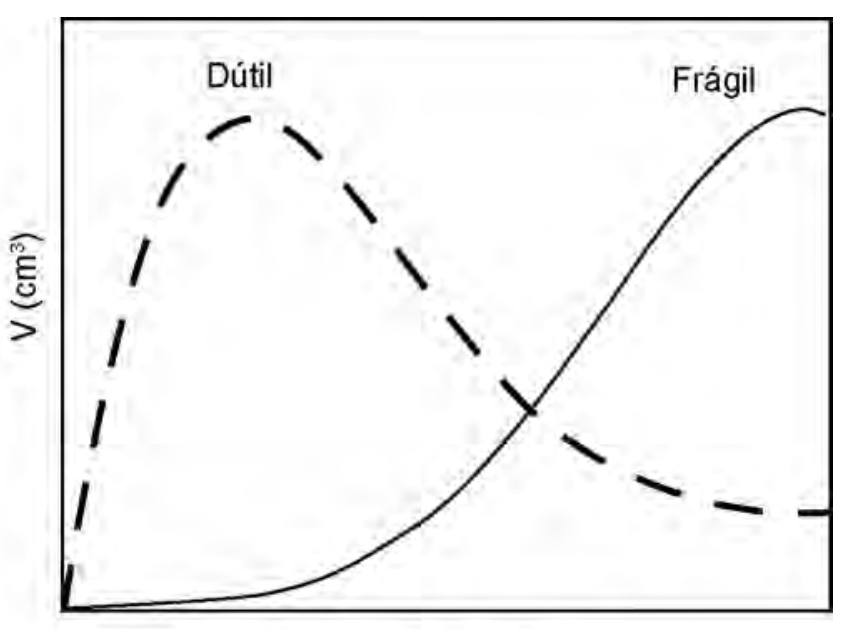

Ângulo de impacto $\left({ }^{\circ}\right)$

Figura 6: Desgaste erosivo de materias dúteis e frágeis em função do ângulo de impacto [5].

[Figure 6: Erosive wear of ductile and brittle materials as fuction of the angle of impingement [5].]

sido o desvio apresentado entre os ensaios, provavelmente devido ao menor volume erodido, gerando resultados mais dispersos. A redução no ângulo de impacto leva a formação de canais preferenciais de desgaste, à medida que a matriz sofre a erosão, na região entre os agregados. Entretanto, se o ângulo de impacto se tornar menor que um valor crítico, estes canais preferenciais são protegidos pelos agregados, por meio do "efeito sombra", o que explica o menor desgaste sofrido pelo material com diminuição do ângulo de impacto do material erosivo.

Na Fig. 7 é mostrada a influência de diferentes tipos de agentes erosivos na resistência à erosão do concreto CA. A Tabela I apresenta as propriedades e características dos materiais erosivos utilizados: carbeto de silício, alumina

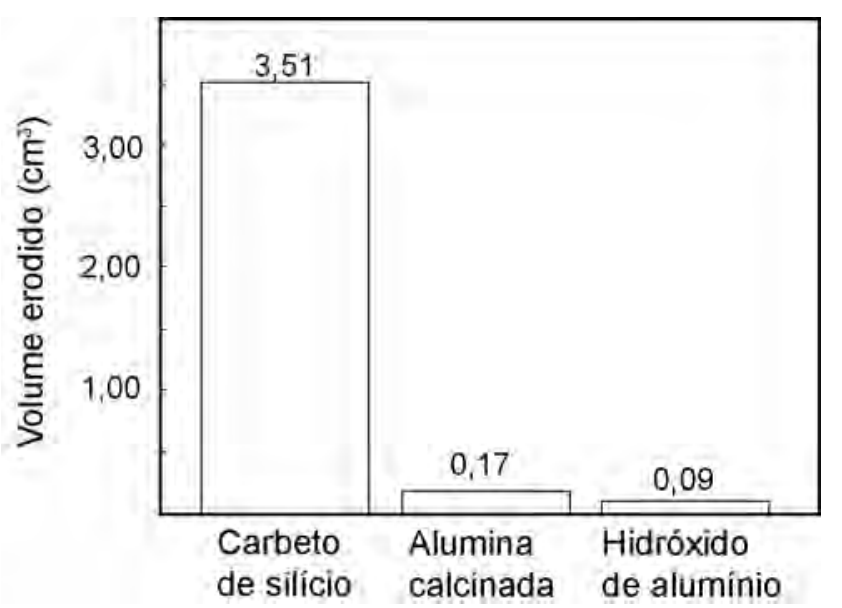

Figura 7: Efeito do tipo de partícula na erosão do concreto A. [Figure 7: Effect of particle type on the erosion of castable A.]
Tabela I - Propriedades dos materiais erosivos.

[Table I-Properties of erosive media.]

\begin{tabular}{cccccc}
\hline $\begin{array}{c}\text { Material } \\
\text { Erosivo }\end{array}$ & $\begin{array}{c}\text { Massa } \\
\text { Específica }\end{array}$ & $\begin{array}{c}\text { Dureza } \\
\text { Mohs } \\
\left(\mathrm{g} / \mathrm{cm}^{3}\right)\end{array}$ & \multicolumn{3}{c}{$\begin{array}{c}\text { Distribuição de } \\
\text { tamanho de } \\
\text { partículas }(\mu \mathrm{m})\end{array}$} \\
\hline $\begin{array}{c}\text { Carbeto de } \\
\text { Silício }\end{array}$ & 3,17 & 9,5 & 310 & 390 & 425 \\
$\begin{array}{c}\text { Alumina } \\
\text { Calcinada }\end{array}$ & 3,50 & 9,0 & 55 & 95 & 150 \\
$\begin{array}{c}\text { Hidróxido } \\
\text { de Alumínio }\end{array}$ & 2,42 & 3,0 & 60 & 100 & 150 \\
\hline
\end{tabular}

calcinada e hidróxido de alumínio.

Nota-se claramente que o $\mathrm{SiC}$ impôs condições muito mais severas de desgaste por erosão. A partir da Equação 1, pode-se afirmar que este comportamento se deve ao maior raio de partícula em relação aos outros dois tipos de agentes erosivos, mesmo apresentando dureza muito próxima ao da alumina. $\mathrm{O}$ decréscimo no tamanho da partícula geralmente causa a diminuição do volume erodido, provavelmente devido a menor energia cinética das partículas com pequeno tamanho [19].

A alumina calcinada, apesar de apresentar distribuição de tamanho de partículas semelhante ao hidróxido de alumínio, possui valores de dureza e de massa específica aparente superiores, resultando em uma maior capacidade em provocar desgaste por erosão.

Na Fig. 8 são apresentados os valores de porosidade e de variação de volume por erosão para as três massas plásticas (CA, CB e CC), o concreto refratário (CG), a lajota silicoaluminosa (LSA) e o vidro soda-cal (V).

O vidro, com porosidade nula, apresentou resistência ao

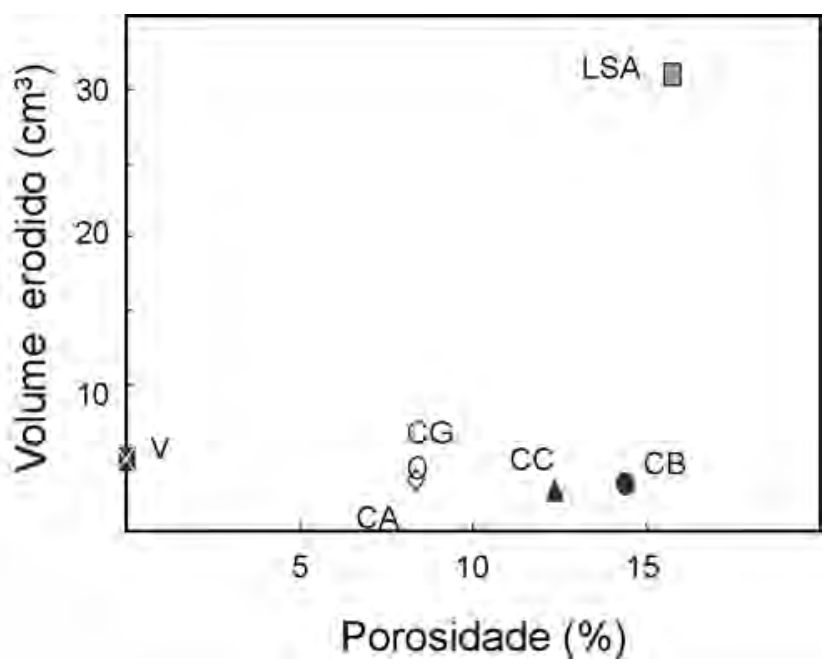

Figura 8: Volume erodido e porosidade de seis tipos de materiais. [Figure 8: Erosion loss and porosity of tested materials.] 
desgaste por erosão inferior às massas plásticas avaliadas e ao CG. Embora estes resultados possam ser animadores, o fato de o vidro apresentar baixo fator de intensidade de tensão crítico $\left(\mathrm{K}_{\mathrm{IC}}\right)$, poderia causar o início e à propagação de trincas em uso contínuo. Esperava-se o aumento do desgaste por erosão com o aumento da porosidade. No entanto, isso não foi observado. As massas plásticas apresentaram resistência à erosão muito semelhante, apesar dos valores distintos de porosidade. Uma das possíveis explicações para tal comportamento estaria relacionada aos diferentes tipos de ligantes usados em cada um dos materiais e, conseqüentemente, distintas durezas do corpo cerâmico. Além disso, o tamanho, a natureza e a distância dos agregados presentes em cada massa plástica podem estar influenciando na resistência a erosão destes materiais.

As três massas plásticas utilizadas em unidades de fabricação de alumínio e em petroquímicas (CA, CB e $\mathrm{CC})$ e o concreto refratário (CG) foram analisados quanto à influência da temperatura a que foram submetidas como mostrado na Fig. 9.

O material CB apresenta um elevado desgaste quando pré-queimado a $400{ }^{\circ} \mathrm{C}$ e uma melhora significativa quando pré-queimado a 600 e $800{ }^{\circ} \mathrm{C}$. Estes resultados indicam a necessidade de se efetuar um tratamento térmico prévio a uma temperatura superior a $400{ }^{\circ} \mathrm{C}$ para maximizar a resistência à erosão destes refratários. O uso do material CA indica a possibilidade de se economizar energia, uma vez que sua resistência a erosão permanece praticamente constante por todo o intervalo de temperatura avaliado. No entanto, havendo a necessidade de queima, para se compatibilizar com outros materiais usados no projeto de revestimento do equipamento, o tratamento térmico não lhe trará prejuízo. $\mathrm{O}$ material $\mathrm{CG}$ tem sua resistência reduzida com o tratamento térmico. O material CC, por outro lado, melhora sensivelmente suas propriedades após a pré-queima nas temperaturas utilizadas.

As massas plásticas refratárias comerciais avaliadas neste estudo apresentaram similares valores de resistência

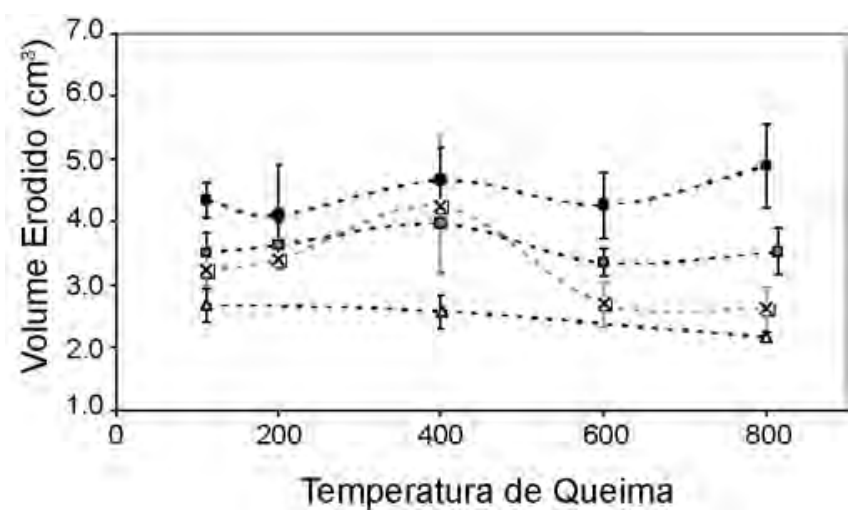

Figura 9: Efeito do tratamento térmico no desgaste por erosão de concretos refratários

[Figure 9: Effect of thermal treatments on erosive wear of refractory castables.] ao desgaste por erosão. Estes materiais têm sido uma opção válida no controle do desgaste por erosão em linhas de transferência de processos industriais. Desenvolvimentos nesta área podem trazer melhorias consideráveis nestes processos.

Visando a caracterização completa dos efeitos de cada um dos parâmetros envolvidos, estudos mais aprofundados têm sido realizados com o intuito de se projetar a composição de um material com elevada resistência à erosão e adequada relação custo-benefício. Desta forma, pretende-se colaborar com a otimização do processo produtivo por meio da redução do tempo de manutenção, devido à minimização de desgastes prematuros nos revestimentos refratários.

\section{CONCLUSÕES}

A partir dos resultados obtidos, pode-se concluir que o desgaste por erosão torna-se menor com a redução na pressão de linha de ar, ou seja, com a redução da velocidade da partícula. O ângulo de impacto também influencia no desgaste por erosão, uma vez que, com a sua redução, a "sombra" dos agregados mais proeminentes passa a proteger a matriz, minimizando o desgaste. Além disso, foi observado que o aumento no tamanho e na dureza da partícula resulta em um maior desgaste por erosão.

Adicionalmente, o procedimento experimental e o equipamento se mostraram úteis na obtenção de um estado de equilíbrio superficial. Conclui-se que a etapa de retificação possibilita que o ensaio seja realizado em um nível de profundidade do corpo de provas que não sofra influência da superfície.

No entanto, a principal conclusão é que a temperatura na qual o material foi pré-queimado pode causar mudanças nas características dos aditivos ligantes e das matérias primas usadas neste material e, conseqüentemente, alterar de maneira significativa sua resistência ao desgaste por erosão.

\section{AGRADECIMENTOS}

Os autores agradecem a CAPES pelo suporte oferecido e a Alcoa Alumínio S.A. e a Treibacher Schleifmittel Brasil pelo material gentilmente cedido.

\section{REFERÊNCIAS}

[1] S. Wiederhorn, Refract. Appl. 2, 1 (1997) 2.

[2] J. Foster, Key Eng. Mater. 122-124 (1996) 247.

[3] ASTM G 40-95, "Standard Terminology Relating to Wear and Erosion", ASTM International.

[4] L. Resen, The Oil and Gas J. 55, 49 (1957) 101.

[5] A. W. Ruff, S. M. Wiederhorn, Erosion by Solid Particle Impact, in Treatise on Materials Science and Technology, Ed. H. Herman, Materials Erosion, vol.16, Ed. C. M. Preece, Academic Press Inc., New York (1979) p. 69.

[6] H. L. Oh, K. P. L. Oh, S. Vaidyanathan, I Finnie, On the 
Shaping of Brittle Solids by Erosion and Ultrasonic Cutting, in The Science of Ceramic Machining and Surface Finishing, Eds. B. J. Hockey, R. W. Rice, National Bureau of Standards Special Publication, Washington D. C. (1970) p. 348.

[7] W. Weibull, Royal Swedish Institute for Engineering Research Proceedings, vol. 151 (1939)

[8] B. R. Lawn, Fracture of Brittle Solids, Cambridge University Press, Cambridge (1993) p. 257.

[9] A. G. Evans, M. E. Gulden, M. E. Rosenblatt - Proc. Royal Society A, London, 361 (1978) p. 343.

[10] S. M. Wiederhorn, B. R. Lawn, J. Am. Ceram. Soc. 62 (1979) 66.

[11] S. M. Wiederhorn, Proc. Corrosion/Erosion of Coal Conversion System Materials (1979) p. 444.

[12] NBR 13186:1994 - Materiais refratários densos

- Determinação da resistência à erosão à temperatura ambiente.

[13]NBR 8382:1997 - Materiais refratários não-conformados - Preparação de corpos-de-prova de concretos para projeção e concretos isolante e denso.

[14] NBR 6946:1994 - Material refratário - Determinação granulométrica por peneiramento de matérias-primas refratarias e refratários não-conformados - Método de ensaio

[15] R. G. Pileggi, V. C. Pandolfelli, A. E. Paiva, J. Gallo, Am. Ceram. Soc. Bull. 79, 1 (2000) 54

[16] U. Engman, Wear 186-187 (1995) 215.

[17] G. L. Barna, R. R. Riley, Am. Ceram. Soc. Bull. 46, 9 (1967) 824.

[18] I. Finnie, Symp. Erosion and Cavitation, ASTM Special Technical Publication, 307 (1962).

[19] M. S. Crowley, Am. Ceram. Soc. Bull. 48, 7 (1969) 707.

(Rec. 09/07/2005, Rev. 19/12/2005, Ac. 03/02/2006) 